Revista Brasileira de Agricultura Irrigada v.11, no.3, p. 1438 - 1447, 2017

ISSN 1982-7679 (On-line)

Fortaleza, CE, INOVAGRI - http://www.inovagri.org.br

DOI: $10.7127 /$ rbai.v11n300573

Protocolo 573.17 - 15/02/2017 Aprovado em 04/05/2017

\title{
PARÂMETROS HÍDRICO, QUÍMICO E CLIMÁTICO EM AMBIENTE CULTIVADO COM CANA-DE-AÇÚCAR SOB EXCESSO DE ÁGUA NO SOLO ${ }^{1}$
}

Antonio Clarette Santiago Tavares ${ }^{2}$, Sergio Nascimento Duarte ${ }^{3}$, Jarbas Honorio de Miranda ${ }^{3}$, Nildo da Silva Dias ${ }^{4}$, Jonath Werissimo da Silva Gomes ${ }^{5}$, Cleyton dos Santos Fernandes ${ }^{6}$

\section{RESUMO}

Praticamente toda cana-de-açúcar produzida no Estado de São Paulo é cultivada em condições de sequeiro e o aproveitamento de novas áreas para sua produção, nas quais haja necessidade de drenagem, pode tornar-se importante. O objetivo deste estudo foi investigar a resposta de diferentes velocidades de rebaixamento do nível freático sobre os parâmetros hídrico, químico e climático do solo em ambiente cultivado com cana-de-açúcar (Saccharum officinarum L., cv. RB867515) para diferentes estádios de desenvolvimento da planta. Um experimento em ambiente protegido foi conduzido em delineamento de blocos casualizados, arranjado em esquema fatorial $(5 \times 3+1) \times 4$, quais sejam, 5 velocidades de rebaixamento do nível freático (30 cm em 3, 6, 9, 12 e 15 dias) e 3 estádios de desenvolvimento (67, 210 e 300 dias após o plantio - DAP) + um tratamento controle (irrigação sem inundação do solo) com 4 repetições. As análises dos resultados indicam que, entre os 3 estádios de desenvolvimento estudados, o encharcamento iniciado aos 210 DAP resultou nos maiores níveis umidade do solo, enquanto que o solo inundado aos 67 DAP foi considerado o de maior $\mathrm{pH}$, seguido dos estádios 210 e 310 DAP. O potencial de oxiredução aumentou à medida que o teor de umidade do solo diminuiu. A radiação fotossinteticamente ativa (PAR) apresentou diferenças significativas $(p<0,05)$ nas posições dentro da estufa plástica, dias e horários de medição; no entanto, não se diferenciaram entre as seções no ambiente protegido.

Palavras-chave: inundação, cultivar RB867515, nível freático, drenagem agrícola.

\section{WATER, CHEMICAL AND CLIMATE PARAMETERS FROM ENVIRONMENT CULTIVATED WITH SUGAR CANE UNDER SOIL MOISTURE EXCESS}

\footnotetext{
ABSTRACT

Almost all sugar cane produced in Sao Paulo State is grown under rainfed agriculture and the exportation for new cultivated areas, were there is a need for drainage, becomes important. The

${ }^{1}$ Parte da tese do primeiro autor

${ }^{2}$ Professor Doutor do Instituto Federal do Norte de Minas Gerais, Almenara-MG. E-mail: antonioirrigacao@yahoo.com.br.

${ }^{3}$ Professores Doutores da Escola Superior de Agricultura "Luiz de Queiroz", ESALQ/USP, Piracicaba-SP. E-mail: snduarte@usp.br,jhmirand@usp.br.

${ }^{4}$ Professor Doutor da Universidade Federal Rural do Semi-Árido (UFERSA), Mossoró-RN. E-mail: nildo@ufersa.edu.br.

5 Mestrando em Horticultura Tropical na Universidade Federal da Paraíba (UFPB), Pombal-PB. E-mail: jonathwerissimo@gmail.com.

${ }^{6}$ Graduando em Agronomia na Universidade Federal Rural do Semi-Árido (UFERSA). E-mail: cleyton1959@hotmail.com.
} 
COM CANA-DE-AÇÚCAR SOB EXCESSO DE ÁGUA NO SOLO

objective of this study was to investigate the response to different groundwater falling rates over water, chemical and climatic parameters in environment cultivated with sugarcane (Saccharum officinarum L., cv. RB867515) at different plant growth stages. A greenhouse experiment was conducted in a randomized blocks design, arranged in factorial scheme $(5 \times 3+1) \times 4$, this is, 5 falling velocities of the water table ( $30 \mathrm{~cm}$ in 3, 6, 9, 12 and 15 days) and, 3 plant growth stages (67, 210 and 300 days after planting - DAP) + a control (irrigation without waterlogging) with 4 replications. The analysis results indicated that among the 3 plant growth stages studied, 210 DAP resulted in higher soil moisture level, while the waterlogged soils at 67 DAP was found to be with the highest $\mathrm{pH}$ followed by stages 210 and 310 DAP. Average oxidation potentials increased as the soil moisture decreased. Photosynthetically active radiation (PAR) had significant differences in different positions inside the plastic greenhouse, days and times measurement, however, they did not differentiate between sections of the greenhouse.

Keywords: water logging, cultivar RB867515, water table, agricultural drainage.

\section{INTRODUÇÃO}

Existem expressivas áreas produtivas do território brasileiro, potencialmente aptas para o cultivo da cana-de-açúcar, onde há problemas relacionados à deficiência natural de drenagem. Dentre estas áreas destacamse as várzeas, as áreas localizadas à meia encosta sujeitas à interferência temporária do lençol freático, as situadas em topografia desfavorável sujeitas à acúmulo temporário de água do escoamento superficial e, ainda, solos em recuperação, degradados pelo manejo excessivo, ou ainda áreas em terras altas cujos solos são de estrutura ou textura que conferem baixa capacidade de infiltração de água, etc. Estes problemas podem ser corrigidos de forma economicamente viável, garantindo, concomitantemente, que os impactos decorrentes da nova forma de exploração sejam minimizados.

Para sanar a deficiência de drenagem natural e permitir o cultivo sustentável da cana, têm sido instalados sistemas de drenagem em vários Estados. Entretanto, estes sistemas são, geralmente, projetados empiricamente com base na experiência prática do projetista ao invés de fazerem uso de critérios técnicos racionais. $\mathrm{O}$ uso desses procedimentos empíricos tem levado ao insucesso do cultivo da cana em muitas áreas de cultivo.

Geralmente, o fator mais limitante à obtenção de espaçamentos corretos entre os drenos concentra-se na falta de um critério de drenagem adequado à cultura. Trabalhos disponíveis na literatura têm demonstrado que a sensibilidade das culturas ao excesso de umidade do solo depende principalmente do clima da região e do estádio fenológico (TAVARES et al., 2015).

Dessa forma, é necessário identificar o estádio mais restritivo e a velocidade média mínima de rebaixamento do lençol freático que não interfira no potencial de produtividade da cultura, de forma que as equações de espaçamento possam ser aplicadas com segurança.

Desse modo, objetivou-se avaliar os efeitos de diferentes velocidades de rebaixamento do nível freático aplicados em três estágios de desenvolvimento sobre os parâmetros hídricos, químicos e climáticos em solo de ambiente cultivado com canade-açúcar.

\section{MATERIAL E MÉTODOS}

O experimento foi conduzido em ambiente protegido no Departamento de Engenharia de Biossistemas da Escola Superior de Agricultura "Luiz de Queiroz" (ESALQ/USP), no município de Piracicaba - SP (22 $42^{\prime}$ de latitude sul e $47^{\circ} 38^{\prime}$ de longitude oeste e altitude de $540 \mathrm{~m}$ ).

A cana-de-açúcar foi cultivada em lisímetros de drenagem, com 1,2 m 
de altura e 0,5 m de diâmetro, e área útil plantada de $0,20 \mathrm{~m}^{2}$, sendo o volume útil de $240 \mathrm{~L}$, onde cada lisímetro representava uma unidade experimental. A entrada da água nas parcelas ocorria pela parte inferior dos lisímetros, derivada de reservatórios móveis de PVC, que permitiam manter o nível freático no interior dos tubulões na profundidade desejada, proporcionando a condição de inundação.

O solo utilizado no preenchimento dos lisímetros foi coletado em um perfil classificado como Latossolo Vermelho Amarelo, de textura franco-arenosa, denominado Série Sertãozinho, retirado do seu local natural na camada de 0 a $0,50 \mathrm{~m}$ (Tabela 1).

A calagem do solo foi realizada na ocasião do preenchimento dos $0,80 \mathrm{~m}$ de solo útil dos lisímetros, aplicando-se $40 \mathrm{~g}$ por lisímetro de calcário dolomítico $(2 \mathrm{Mg}$ $\mathrm{ha}^{-1}$ ), homogeneizado ao solo em camadas a partir dos $0,50 \mathrm{~m}$, de baixo para cima, corrigindo uma camada total de solo de $0,30 \mathrm{~m}$.

A adubação química foi parcelada em 3 vezes utilizando-se as seguintes doses por hectare: $67 \mathrm{~kg}$ de N, $180 \mathrm{~kg}$ de $\mathrm{P}_{2} \mathrm{O}_{5}$ e $225 \mathrm{~kg}$ de $\mathrm{K}_{2} \mathrm{O}$, o que correspondeu a 10,5 ; 20 e $10 \mathrm{~g}$ por lisímetro, respectivamente. O nitrogênio e o potássio foram aplicados aos $40 ; 110$ e 220 DAP, utilizando nitrato de potássio. Aos 150 DAP foi incorporado $5 \mathrm{~kg}$ de matéria orgânica em cada parcela, visando melhorar a aeração na camada superficial do solo.

A cana-de-açúcar foi irrigada ao longo do ciclo via sistema de sub-irrigação, exceto no período em que os tratamentos com inundação foram aplicados, garantindo que as diferenças obtidas fossem proporcionadas apenas pelo estresse por excesso de umidade (hipoxia). Após aplicados os tratamentos, rebaixava-se o NF até a 0,80 $m$ da superfície do solo e a irrigação destas plantas recomeçava no momento em que o valor das leituras de tensiômetros instalados a $0,30 \mathrm{~m}$ de profundidade nos lisímetros atingia o valor de $50 \mathrm{kPa}$.

As avaliações dos parâmetros climáticos, hídricos e químicos foram realizadas nos períodos aos 67, 210 e 305 DAP $\left(\mathrm{P}_{1}, \mathrm{P}_{2}\right.$ e $\mathrm{P}_{3}$, respectivamente). As parcelas existentes em cada lisímetro eram submetidas a diferentes velocidades de rebaixamento do NF (V), isto é, inundação e posterior rebaixamento do nível freático de $0,3 \mathrm{~m}$ em 3, 6, 9, 12 e 15 dias $\left(\mathrm{V}_{1}, \mathrm{~V}_{2}\right.$, $\mathrm{V}_{3}, \mathrm{~V}_{4}$ e $\mathrm{V}_{5}$, respectivamente), obtendo as seguintes combinações: $\mathrm{P}_{1} \mathrm{~V}_{1}, \mathrm{P}_{1} \mathrm{~V}_{2}, \mathrm{P}_{1} \mathrm{~V}_{3}$, $\mathrm{P}_{1} \mathrm{~V}_{4}, \mathrm{P}_{1} \mathrm{~V}_{5}, \mathrm{P}_{2} \mathrm{~V}_{1}, \mathrm{P}_{2} \mathrm{~V}_{2}, \mathrm{P}_{2} \mathrm{~V}_{3}, \mathrm{P}_{2} \mathrm{~V}_{4}, \mathrm{P}_{2} \mathrm{~V}_{5}$, $\mathrm{P}_{3} \mathrm{~V}_{1}, \mathrm{P}_{3} \mathrm{~V}_{2}, \mathrm{P}_{3} \mathrm{~V}_{3}, \mathrm{P}_{3} \mathrm{~V}_{4}$ e $\mathrm{P}_{3} \mathrm{~V}_{5}$

Em função da atenuaçã̃o da radiação natural causada pela cobertura da casa de vegetação, utilizou-se o Sunscan Canopy Analysis System type SS1 da Delta - T Devices Ltd. para quantificar a radiação fotossinteticamente ativa (PAR) presente no interiordoambienteprotegido.Considerando que há variação microclimática no interior de estufas plásticas, dividiu-se o ambiente interior em três secções (entrada, meio e fundo), de forma a caracterizar a intensidade de radiação em cada segmento. Para cada secção do ambiente foram feitas oito leituras, quatro em cada seção e em três horários distintos (8:00, 12:00 e 16:00 horas). Também foi feita a avaliação da radiação que atingia o topo das copas das plantas e aquela ao nível do solo dos lisímetros, em dois dias consecutivos.

Para quantificação dos parâmetros hídricos, instalaram-se tensiômetros a 0,30 $\mathrm{m}$ de forma a caracterizar a umidade no

Tabela 1. Análise granulométrica e química do solo utilizado no preenchimento dos lisímetros.

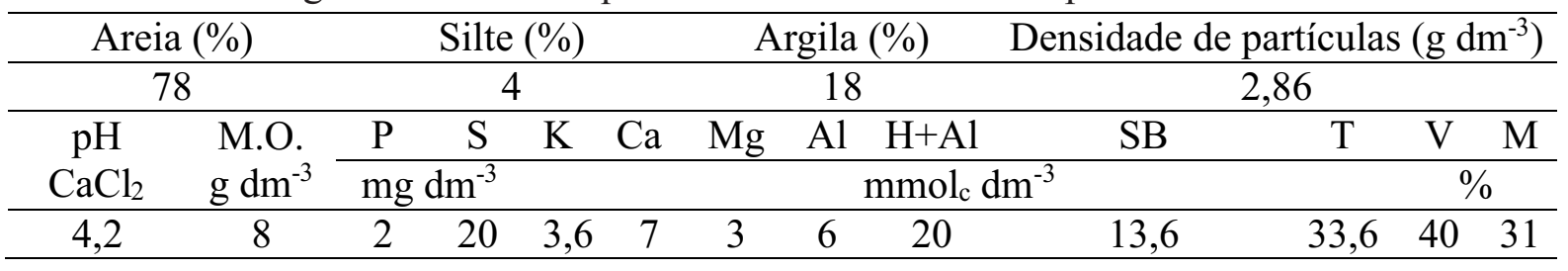


sistema radicular das plantas. As medições ocorreram por um período de 20 dias consecutivos posteriormente aos períodos de inundação.

Em cada parcela experimental, a umidade do solo foi estimada a partir da curva característica de retenção da água no solo e das médias das leituras tensiométricas a $0,30 \mathrm{~m}$ de profundidade. Os dados de retenção da água do solo foram ajustados a uma curva pelo modelo potencial.

Os parâmetros químicos foram estimados em poços de observação (tubos verticais furados de $50 \mathrm{~mm}$ cravados no solo). Para as medidas de $\mathrm{pH}$ e do potencial de oxiredução do solo utilizaram-se pHgâmetro Portátil e eletrodo de redox, respectivamente. Antes de cada leitura eram feitas calibrações com as soluções tampões pH 6,86, Modelo DM-S1A, Solução Tampão pH 4,01, Modelo DM-S1B e Solução Padrão de Redox $475 \mathrm{mV}$ a $25^{\circ} \mathrm{C}$, Modelo DM-S7A, respectivamente.

Os resultados foram submetidos à análise de variância e teste de médias empregando Tukey para os dados qualitativos (tratamentos, período e dias) e análise de regressão para os efeitos das velocidades.

\section{RESULTADOS E DISCUSSÃO}

\section{Umidade do solo}

Obtida a curva característica do solo, definiu-se a umidade de saturação em 0,39 $\mathrm{cm}^{3} \mathrm{~cm}^{-3}$ e a umidade na capacidade de campo em $0,28 \mathrm{~cm}^{3} \mathrm{~cm}^{-3}$ para um potencial de água no solo de $8 \mathrm{kPa}$ (Figura 1).

No primeiro período de inundação, após um dia, registrou-se teor máximo de umidade de $0,56 \mathrm{~cm}^{3} \mathrm{~cm}^{-3}$ nos solos que sofreram a influência do encharcamento e de $0,32 \mathrm{~cm}^{3} \mathrm{~cm}^{-3}$ no solo da parcela testemunha De acordo com Van Genuchten (1980), esses valores de umidade do solo próximos à capacidade de campo se deve ao fato que as parcelas que continham as plantas testemunhas recebiam somente

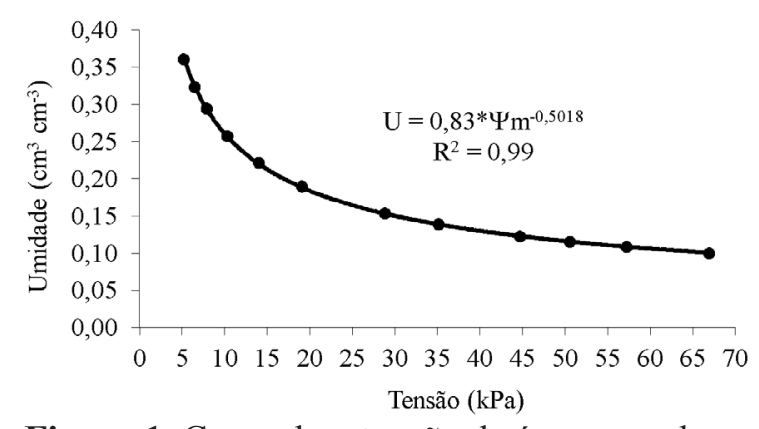

Figura 1. Curva de retenção da água no solo.

água de irrigação. No final do período de avaliação, os valores médios dos teores de umidades dos solos das parcelas inundadas foram reduzidos $\left(0,22 \mathrm{~cm}^{3} \mathrm{~cm}^{-3}\right)$, ficando abaixo da testemunha $\left(0,34 \mathrm{~cm}^{3} \mathrm{~cm}^{-3}\right)$, caracterizando o rebaixamento do NF próximo a $0,30 \mathrm{~m}$ que comporta o sistema radicular efetivo da cana-de-açúcar (Figura 2A).

Para o segundo período de inundação, os valores de umidades iniciais (1 dia após a inundação) variaram de 0,33 a 0,67 $\mathrm{cm}^{3} \mathrm{~cm}^{-3}$ para as parcelas não inundadas e inundadas $\left(\mathrm{P}_{2} \mathrm{~V}_{3}\right)$, respectivamente (Figura 2B). No entanto, aos 20 dias após a inundação, os teores médios de umidades do solo, na profundidade de $0,30 \mathrm{~m}$, foram reduzidos para $0,27 \mathrm{~cm}^{3} \mathrm{~cm}^{-3}$ em condições de inundação, próximo ao tratamento testemunha $\left(0,23 \mathrm{~cm}^{3} \mathrm{~cm}^{-3}\right)$.

No início do terceiro período de avaliações, os valores médios de umidade nas parcelas que foram submetidas à inundação apresentaram teores variando entre 0,20 a $0,80 \mathrm{~cm}^{3} \mathrm{~cm}^{-3}$, enquanto nas parcelas irrigadas (testemunhas), encontravam-se teores médios de umidade de $0,21 \mathrm{~cm}^{3} \mathrm{~cm}^{-3}$ (Figura 2C); isso possivelmente ocorreu devido a suspensão da irrigação 40 dias antes da colheita, motivo o qual, no final do período de avaliação, ocorreu o distanciamento dos valores de umidades detectado nas parcelas inundadas em relação aos valores encontrados nas parcelas submetidas à irrigação.

Vale salientar que, mesmo após rebaixar o NF além dos $0,30 \mathrm{~m}$, o rebaixamento continuou até chegar aos 0,80 $\mathrm{m}$ de profundidade, de forma gradativa, 


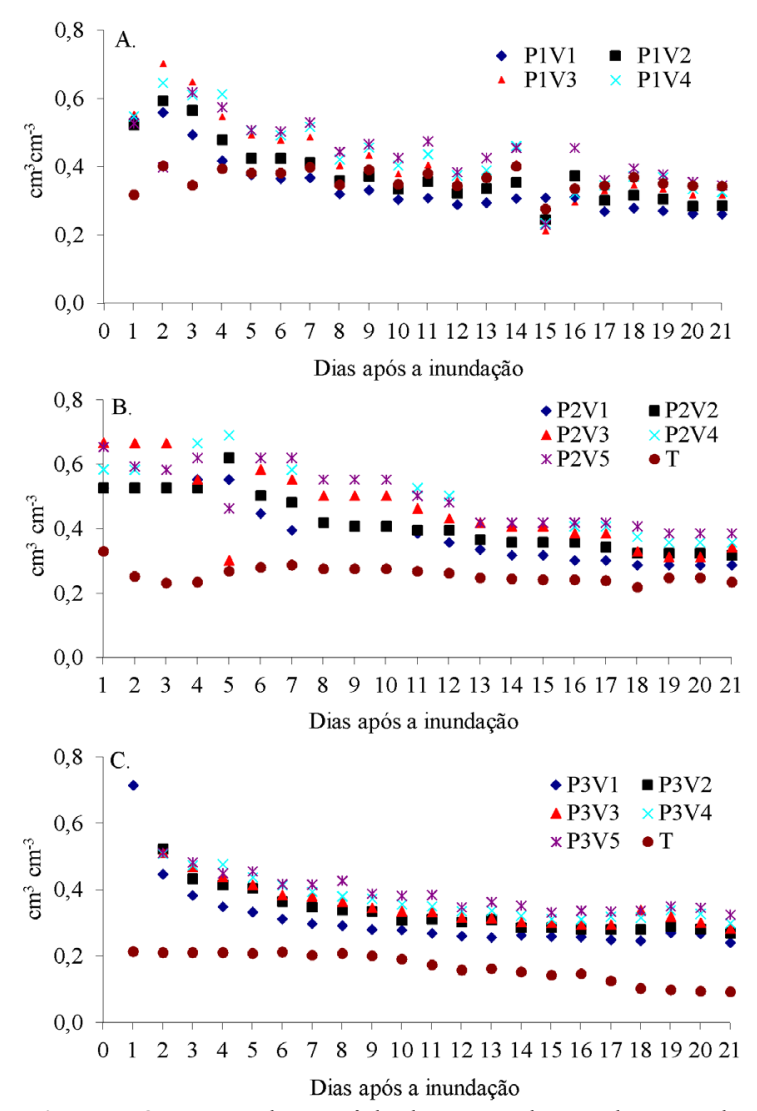

Figura 2. Teor de umidade no solo ao longo de 20 dias de avaliação, durante o primeiro (A), segundo (B) e terceiro (C) período de inundação das parcelas.

conforme Figura 3. O tempo gasto para rebaixar o NF a $0,80 \mathrm{~m}$ variou de 24 dias para a velocidade de rebaixamento de $0,3 \mathrm{~m}$ em 3 dias a 140 dias para a menor velocidade, $0,3 \mathrm{~m}$ em 15 dias.

\section{pH e potencial de oxiredução}

De acordo com a ANOVA, a velocidade de rebaixamento do NF proporcionou uma condição de intensidade de encharcamento ao solo. As variáveis $\mathrm{pH}$ e potencial de oxiredução foram influenciadas significativamente por todas as fontes de

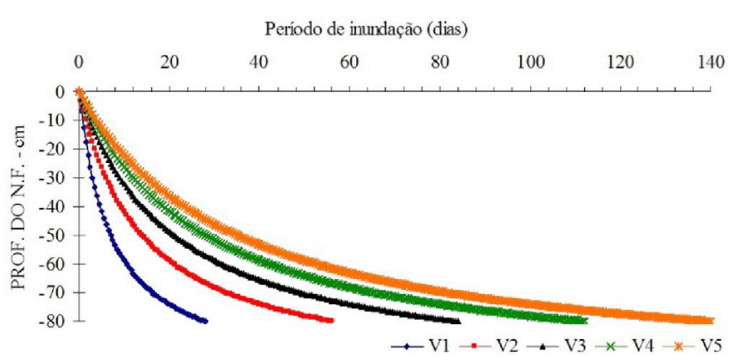

Figura 3. Rebaixamento progressivo do NF na profundidade de $30 \mathrm{~cm}$ em 3, 6, 9, 12 e 15 dias. variação, exceto o fator velocidade (Tabela 2).

As parcelas que foram submetidas ao primeiro período de inundação $\left(\mathrm{P}_{1}\right)$, apresentaram maiores valores de $\mathrm{pH}$, valores esses observados aos 47 dias após o plantio (Figura 4). Nessas parcelas, o pH do solo se manteve neutro ou próximo da neutralidade. Essa condição pode ter sido ocasionada devido à calagem do solo antes do plantio da cana-de-açúcar, que sob condição de inundação, ocasionou as reações químicas liberando as bases e neutralizando a acidez do solo.

Camargo et al. (1993) afirmam que a calagem aumenta o $\mathrm{pH}$ de solos ácidos devido à sua redução, enquanto que em

Tabela 2. ANOVA para as variáveis $\mathrm{pH}$ e potencial de oxiredução $(\mathrm{mV})$ medidos nas parcelas submetidas ao encharcamento com diferentes velocidades de o rebaixamento do nível freático nos períodos de 67,210 e 305 DAP.

\begin{tabular}{|c|c|c|c|}
\hline \multirow[t]{2}{*}{ Causas de variação } & GL & $\mathrm{pH}$ & $\begin{array}{c}\text { Potencial } \\
\text { Redox }\end{array}$ \\
\hline & \multicolumn{3}{|r|}{ QM } \\
\hline Tratan & 14 & $0,87^{* *}$ & $947243,25^{* *}$ \\
\hline Períoc & 2 & $5,51^{* *}$ & $6016530,46^{* *}$ \\
\hline Velocid & 4 & $0,07^{\text {ns }}$ & $166532,47^{* *}$ \\
\hline Dias & 8 & $0,51^{* *}$ & $449153,36^{* *}$ \\
\hline Tratamentos x Dias & 120 & $0,09^{* *}$ & $49899,12^{* *}$ \\
\hline Períod & 16 & $0,34^{* *}$ & $95486,43^{* *}$ \\
\hline Bloc & 3 & $0,08^{\text {ns }}$ & $11353,50^{\mathrm{ns}}$ \\
\hline Resíduo & 402 & 0,04 & 8384,56 \\
\hline Total & 539 & & \\
\hline CV $(\%)$ & & 2,90 & 67,18 \\
\hline Média geral & & 6,89 & 136,49 \\
\hline
\end{tabular}

**e ns significativo e não significativo ao nível de 0,05 de probabilidade pelo teste $\mathrm{F}$, respectivamente.

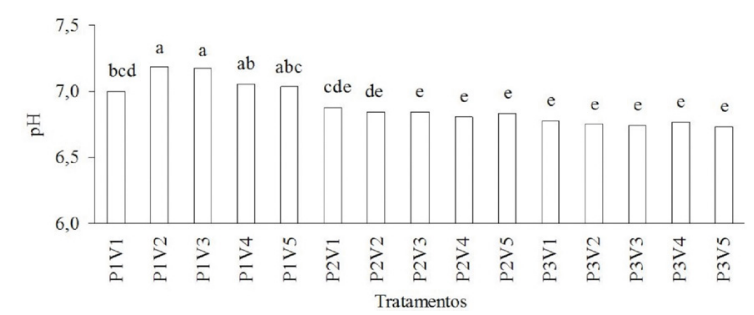

Valores médios seguidas da mesma letra não diferem estatisticamente pelo teste de Tukey a 5\% de probabilidade.

Figura 4. pH do solo para os tratamentos. 
solos alcalinos, observa-se o decréscimo do $\mathrm{pH}$ devido à acumulação mais intensa de $\mathrm{CO}_{2}$, fazendo com que a maioria dos solos inundados se encontrem em valores próximos à neutralidade.

Ao longo do ciclo cultural da canade-açúcar houve decréscimo no poder corretivo do calcário no solo, uma vez que as condições de encharcamento aceleram as reações de neutralização propiciando um ambiente favorável para as plantas crescerem e extrair os nutrientes necessários ao seu desenvolvimento, tendendo a condição inicial (Figura 5A). Pode também, ter havido a influência da aplicação da ureia por cobertura.

Nos dias de avaliação dentro dos períodos aos quais as plantas estiveram submetidas ao encharcamento, os valores médios de $\mathrm{pH}$ diferenciaram-se apenas no dois primeiros dias, mantendo-se iguais no restante dos dias avaliados, mas apresentando um tendência de redução a partir do oitavo dia de inundação (Figura 5B).

$\mathrm{O}$ potencial médio de oxiredução no solo das parcelas experimentais que

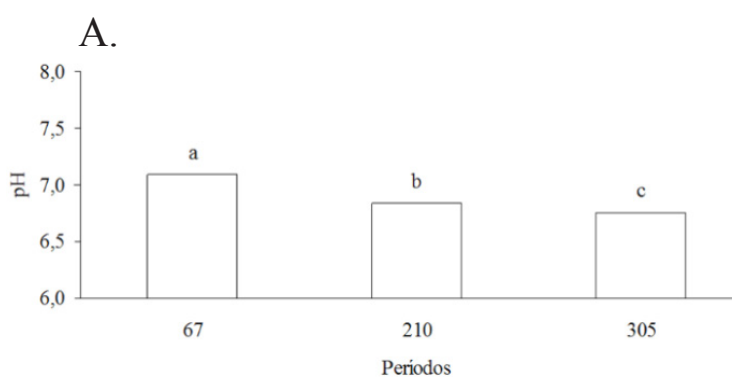

B.

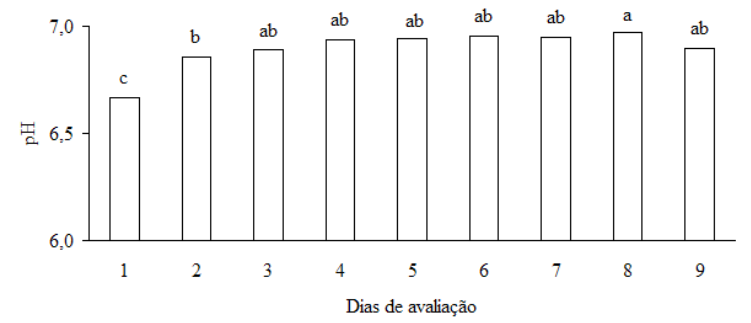

Valores médios seguidas da mesma letra não diferem estatisticamente pelo teste de Tukey a 5\% de probabilidade.

Figura 5. Potencial médio de hidrogênio nas parcelas experimentais submetidas aos diferentes períodos de inundação ao longo do ciclo cultural da cana (A) e durante sucessivos dias de avaliação após a inundação (B). foram submetidas aos tratamentos de encharcamento encontra-se na Figura 6. Os tratamentos apresentaram valores bastante diferenciados, possivelmente em função da absorção dos íons do solo pela planta e também pela adição de matéria orgânica às parcelas experimentais ocorrida aos 150 DAP, que pode explicar os valores médios observados nas leituras feitas nos tratamentos $\mathrm{P}_{2}$ e $\mathrm{P}_{3}$.

Os valores obtidos nas leituras variaram entre 357,60 $\mathrm{mV}$ (extremo superior) para o primeiro período de inundação aos 67 dias após a inundação das parcelas e -59,2 $\mathrm{mV}$ (extremo inferior), segundo período de inundação das parcelas. Observa-se que o terceiro período apresentou valores intermediários entre $166,14 \mathrm{mV}$ (extremo superior) e -14,22 mV (extremo inferior), sendo que os valores negativos foram obtidos nas parcelas que estiveram submetidas a uma menor velocidade de rebaixamento (Figura 6), ou seja, encharcamento mais prolongado.

Calheiros et al. (2000), trabalhando em um solo Podzólico Vermelho-Amarelo abrupto cultivado com trigo sob condição de encharcamento encontraram um decréscimo do potencial de oxiredução, partindo de uma condição inicial de 100 $\mathrm{mV}$ até alcançar um ponto mínimo de -400 $\mathrm{mV}$, com 5,5 h de excesso umidade. Em seguida, esses autores observaram uma elevação gradativa, atingindo um ponto intermediário de $-240 \mathrm{mV}$, após 12,5 h.

Aos 67 DAP, o solo das parcelas estavam com baixo teor de matéria

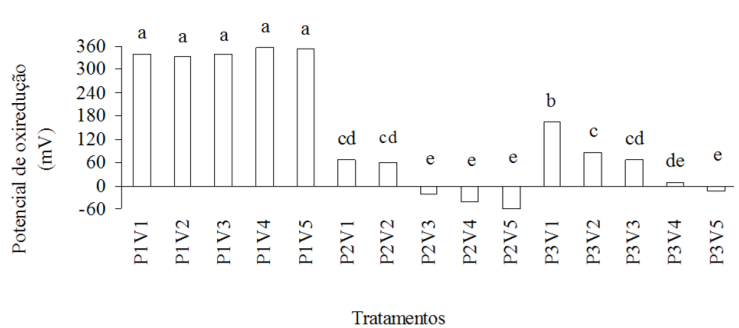

Valores médios seguidas da mesma letra não diferem estatisticamente pelo teste de Tukey a 5\% de probabilidade.

Figura 6. Potencial médio de oxiredução nas parcelas experimentais submetidas aos diferentes tratamentos. 
orgânica, plantas em estádio inicial de crescimento e também submetido a uma condição de calagem. No segundo período de inundação (210 DAP), o solo recebeu adubação orgânica na quantidade de $5 \mathrm{~kg}$ por parcela e o calcário estava em processo de neutralização, uma vez que as parcelas estavam submetidas a irrigação no período anterior a inundação. $\mathrm{O}$ valor médio do potencial de oxiredução encontrado aos 305 dias tornou a aumentar, atingindo valores de $63,47 \mathrm{mV}$, possivelmente, em função da decomposição do material orgânico e da redução do $\mathrm{pH}$ do solo, pois segundo Sidiras e Pavan (1985) teores mais elevados de matéria orgânica amenizam o efeito da acidificação (Figura 7).

Ainda em relação à Figura 7, observase um aumento nos valores médios do potencial de oxirredução à medida que sreduz o teor de umidade na profundidade das leituras, apresentando valores de 37,38 $\mathrm{mV}$ no segundo dia, $121,90 \mathrm{mV}$ no quarto dia, 203,39 $\mathrm{mV}$ no oitavo dia e chegando 298,61 mV no último dia de avaliação. Enquadrando os valores de potencial de oxiredução obtidos nas parcelas inundadas

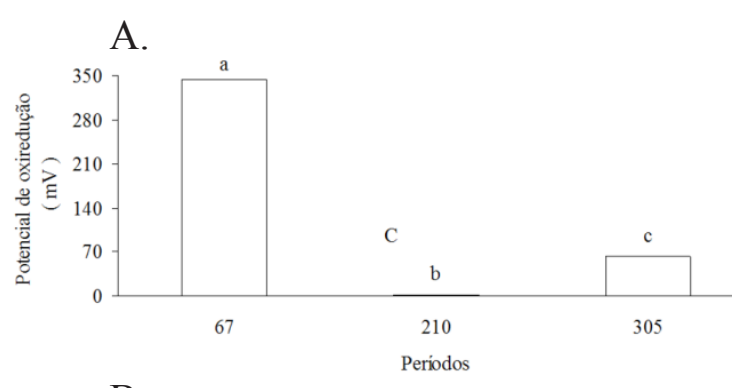

B.

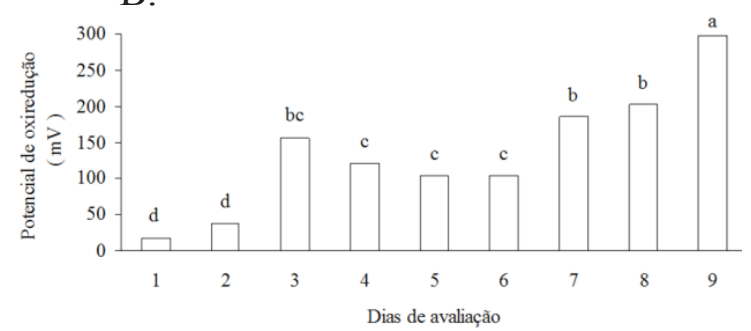

Valores médios seguidas da mesma letra não diferem estatisticamente pelo teste de Tukey a 5\% de probabilidade.

Figura 7. Potencial de oxiredução nas parcelas experimentais sob diferentes períodos de inundação (A) e durante os dias de avaliação após a inundação da cana-de-açúcar (B). ao longo do ciclo da cultura nos três períodos de inundação e submetidas as cinco velocidades de rebaixamento do NF nas faixas de valores sugerida por TianYen (1985), podemos dizer que o solo encontrava-se com redução de fraca a moderada estando as plantas submetidas a condições que ocasionariam o crescimento normal e/ou efeitos maléficos para culturas de sequeiro, respectivamente.

As velocidades de rebaixamento não influenciaram nos valores médios do potencial de oxiredução, apresentando valores médios entre 190,85 e $65,93 \mathrm{mV}$ e com uma tendência visível de decréscimo à medida que se tinha maior umidade do solo, ou seja, nas menores velocidades de rebaixamento (Figura 8). Segundo Farrell et al. (1991), embora a metodologia do potencial oxiredução da solução do solo seja simples (medidas de potencial de eletrodo), a mesma pode estar sujeita a incertezas, sendo as principais referentes ao fato de que os eletrodos de platina, utilizados na determinação do potencial "redox", respondem a mais de uma semireação "redox".

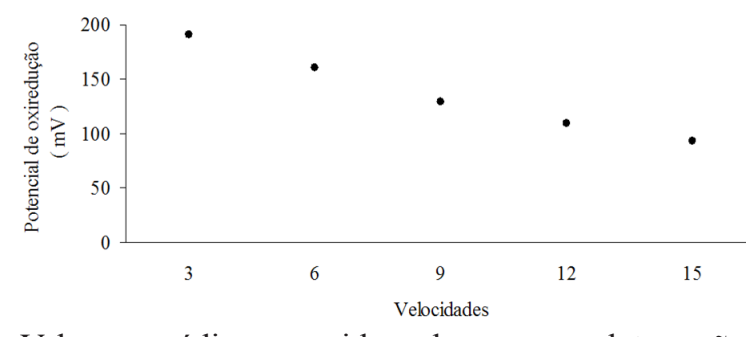

Valores médios seguidas da mesma letra não diferem estatisticamente pelo teste de Tukey a 5\% de probabilidade.

Figura 8. Potencial médio de oxiredução nas parcelas experimentais submetidas às diferentes velocidades de rebaixamento do NF.

\section{Radiação PAR}

De acordo com a análise de variância, houve diferenças significativas da radiação fotossinteticamente ativa (PAR) para os tratamentos, as posições, os horários, os dias, bem como para as interações tratamentos $\mathrm{x}$ dias e tratamentos x posições (Tabela 3).

Os tratamentos propostos apresentaram valores médios de radiação 
COM CANA-DE-AÇÚCAR SOB EXCESSO DE ÁGUA NO SOLO

Tabela 3. Análise de variância para a radiação fotossinteticamente ativa (PAR) no interior da casa de vegetação.

\begin{tabular}{|c|c|c|}
\hline Causas de variação & G.L. & QM \\
\hline Tratamentos & 3 & $635223,24^{* *}$ \\
\hline Posições & 1 & $249172,58^{* *}$ \\
\hline Horários & 2 & $2972604,05^{* *}$ \\
\hline Dias & 1 & $4013195,25^{* *}$ \\
\hline Repetições & 3 & $8033,32^{\text {ns }}$ \\
\hline Tratamentos*Horários & 6 & $105484,68^{* *}$ \\
\hline Tratamentos*Dias & 3 & $111890,92^{* *}$ \\
\hline Tratamentos*Posições & 3 & $7340,02^{\mathrm{ns}}$ \\
\hline Resíduo & 145 & 25972,11 \\
\hline Total & 167 & \\
\hline
\end{tabular}

PAR que diferiram significativamente, apenas quando comparados os valores do interior da casa de vegetação com os valores do ambiente externo. No interior do ambiente não foi observado diferenças significativas nas três secções da casa de vegetação (Figura 9A). Essa condição é justificada devido a densidade de fluxo da radiação solar no interior da estufa ser menor do que a verificada externamente, devido a reflexão e à absorção do material da cobertura plástica, evidencias essas

A.

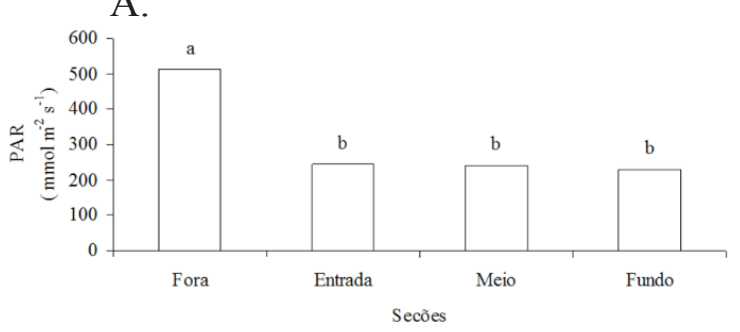

B.

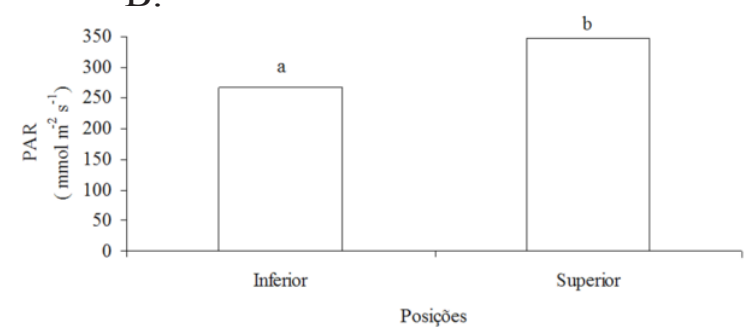

Valores médios seguidos da mesma letra não diferem estatisticamente pelo teste de Tukey a 5\% de probabilidade.

Figura 9. Valores médios de radiação PAR para as diferentes seções da estufa plástica (A) e em posições verticais ao longo do dossel (B). também constatadas em Sousa Neto et al., (2010) e Costa et al. (2016).

Os valores médios de radiação PAR nas duas posições, em sentido vertical, apresentaram-se diferentes estatisticamente (Figura 9B). A interceptação da radiação ao longo do dossel da cultura justifica esses valores distintos.

Os valores de PAR nos diferentes horários de avaliação apresentaram valores médios que diferiram significativamente (Figura 10A). Essa diferença se justifica devido a radiação ao longo do dia apresentar intensidade diferenciada, confirmando os valores obtidos. Nos dois dias em que foram feitas as avaliações os valores médios da PAR também apresentaram diferenças estatísticas (Figura 10B). A diferença de intensidade de radiação observada provavelmente se deve às condições climáticas presentes nos distintos dias. $\mathrm{O}$ segundo dia apresentou-se nublado pela manhã e chuvoso no período vespertino.

$\mathrm{Na}$ Figura 11A estão dispostos os valores da PAR para o desdobramento dos tratamentos para os diferentes dias. Para o ambiente interno à casa de vegetação nos dias que se seguiram, os valores médios da

A.

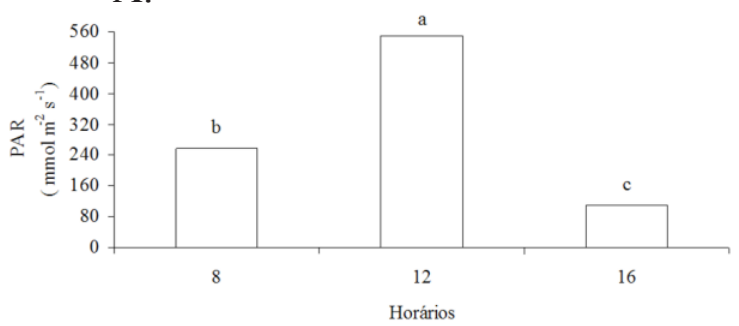

B.

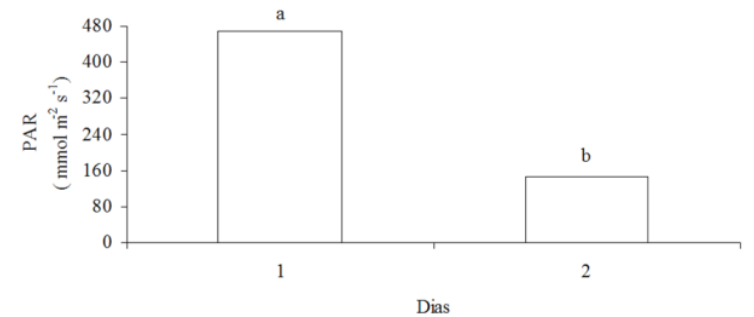

Médias seguidas da mesma letra não diferem estatisticamente pelo teste de Tukey a $5 \%$ de probabilidade.

Figura 10. Valores médios de radiação PAR para os diferentes horários do dia (A) e para os diferentes dias (B). 


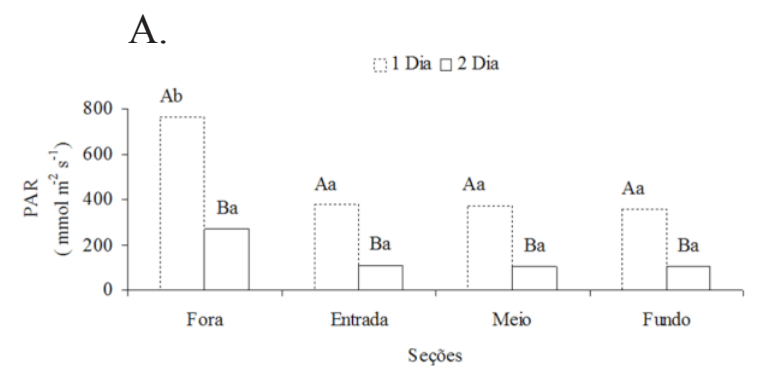

B.

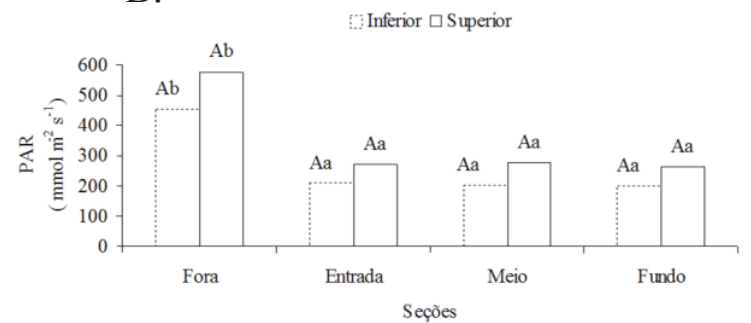

Médias seguidas da mesma letra não diferem estatisticamente pelo teste de Tukey a 5\% de probabilidade, sendo que as letras minúsculas comparam médias na horizontal e as maiúsculas na vertical.

Figura 11. Valores médios de radiação PAR para seções nos diferentes dias (A) e nas diferentes posições (B).

PAR nos tratamentos não diferiram em um mesmo dia. No entanto, no ambiente externo foi detectado diferenças significativas no primeiro dia. Quando se confronta os valores médios da PAR entre os dias para as seções, percebe-se que os valores diferem estatisticamente para todos os tratamentos. Já em relação às posições verticais (Figura 11B), observa-se que, tanto no interior da casa de vegetação como a céu aberto, os valores médios da PAR não diferiram para ambas as posições. No entanto, os valores se mostraram diferentes quando medidos nos distintos ambientes, em função da interceptação da radiação pela cobertura plástica.

\section{CONCLUSÕES}

Os teores de umidade no solo apresentaram maiores valores e variação no encharcamento realizado aos 210 dias após o plantio da cana-de-açúcar;

As condições de encharcamento aceleram as reações de neutralização, o que fica evidenciado pela redução do $\mathrm{pH}$ ao longo do ciclo da cana-de-açúcar expresso nos seus valores obtidos na avaliação nos três períodos de inundação;

O potencial de oxiredução aumentou à medida que se reduziu o teor de umidade do solo;

Os valores de radiação fotossinteticamente ativa variam em função da posição, dos dias e dos horários de medição, mas não se diferenciaram entre as seções no interior do ambiente protegido.

\section{REFERÊNCIAS}

CALHEIROS, R.O.; CRUCIANI, D.E.; ARRUDA, F.B.; VOLTAN, R.B.Q.; SAKAI, E.; PIRES, R.C.M. Efeito do manejo do lençol freático na adaptação fisiomorfológica de duas espécies de trigo ao encharcamento. Revista Brasileira de Engenharia Agrícola e Ambiental, v.4, n.2, p.194-202, 2000.

CAMARGO, F.A.O., SANTOS, G.A., ROSSIELLO, R.O.P. Produção de ácidos orgânicos voláteis pela planta de arroz sob condições anaeróbias. Revista Brasileira de Ciência do Solo, v.17, n.3, p.337-342, 1993.

COSTA, V. M.; FOLEGATTI, M. V. ATARASSI, R. T.; DUARTE, S. N.; DIAS, N. S.; SILVA, C. R. Desenvolvimento de mudas de cafeeiro produzidas em tubetes sob malhas termo-refletoras e malha negra. Irriga, Edição Especial, Grandes Culturas, p.52-65, 2016.

FARRELL, R.E., SWERHONE, G.D.W, KESSEL, C. Construction and evaluation of a reference electrode assembly for use in monitoring in situ soil redox potentials. Communications in Soil Science and Plant Analysis, v.22, p.1059-1068, 1991.

SOUSA NETO, O. N.; DIAS, N. D.; ATARASSI, ROBERTO TERUMI; REBOUÇAS, J. R. L.; OLIVEIRA, A. 
M. Produção de alface hidropônica e microclima de ambiente protegido sob malhas termo-refletoras. Revista Caatinga, v.23, n.4, p.84-90, 2010.

SIDIRAS, N.; PAVAN, M.A. Influencia do sistema de manejo de solo no seu nível de fertilidade. Revista Brasileira de Ciência do Solo, v.9, n.3, p.249-254, 1985.

TAVARES, A. C. S.; DUARTE, S. N.; MIRANDA, J. H.; DIAS, N. S.; SOUZA, K. T. S. S.; ARRAES, F. D. D. Velocidade de rebaixamento do nível freático na qualidade do caldo da cana-de-açúcar. Irriga, v.20, n.3, p.458-472, 2015.

TIAN-YEN, Y. Soil and plants. In: TIANYEN, Y. Physical chemistry of paddy soils. Springer-Verlag, 1985. p. 197-214.

VAN GENUCHTEN, M.T. A closedfrom equation for predicting the hydraulic conductivity of unsaturaded soils. Soil Science Society of America Journal, v.44, n.3, p.892-898, 1980. 